\title{
The Giant Size Parotid Lesions
}

\section{Mario Mannino*, Giorgio Barbera, Davide Soverina, Gemma Mastrantoni, Gianmarco Saponaro, Giulio Gasparini, Sandro Pelo and Alessandro Moro}

Department of Maxillofacial Surgery, Università Cattolica del Sacro Cuore (RM), Italy

*Corresponding Author: Mario Mannino, Department of Maxillofacial Surgery, Università Cattolica del Sacro Cuore (RM), Italy.
Received: December 13, 2021

Published: December 31, 2021

(C) All rights are reserved by Mario Mannino., et al.

\begin{abstract} definition of this term. cal characteristics. were considered and the inclusion criteria were as follows:

- Studies reporting malignant or benign parotid tumors with dimension;

- Definition as "giant", "huge" or other terms that emphasize the dimension of the tumor;

- Primary parotid tumor.
\end{abstract}

Introduction: Parotid tumors are usually slow growing, asymptomatic masses and the average size reported to be between 2 and $6 \mathrm{~cm}$ [9]. In the literature, some cases of "giant tumors" of the parotid are mentioned, most of them benign, but there isn't a clear

This article will examine all the lesions that include the term "giant", trying to find a definition, a size cut-off, epidemiologic and clini-

Materials and Methods: The search of the major databases (PubMed, Cochrane and Scopus) was performed until December 29, 2019. Randomized controlled trials (RCTs), case series, case reports, reviews of the literature, interventional or observational studies

Letters to editor were excluded and the following exclusion criteria were applied:

- $\quad$ Studies without indications about tumor dimension.

Results: The studies included a total of 43 patients with giant parotid tumor. 37 out of 39 articles were case reports and 2 articles were case series.

The size of the lesion depends on the period of time from clinical onset to giant transformation reported (co-gtr).

In 2 cases of malignant tumor the growth was extremely fast.

The correlation between "size" and co-gtr is high and positive (equal to 0.69$)$ and the ratio is statistically significant $(P<0.05)$, that means the larger the size the longer the time since clinical onset to giant transformation reported.

The average detected size was $14.2 \mathrm{~cm}$ and two peaks were found at $6 \mathrm{~cm}$ and $20 \mathrm{~cm}$. (range $3-46 \mathrm{~cm}$ ).

The larger part of the tumours are benignant (75\%), of which pleomorphic adenoma is the most represented (47\%). In the malignant group, half of them are carcinoma ex pleomorphic adenoma.

Conclusion

- The size of the tumors depends on neglection and this does not only apply to underdeveloped countries but also to the western world, being largely linked to the refusal of treatment and perhaps to medical/patient wrong communication.

- Two dimensional peaks were find regarding the metrical size of the lesions. The first peak was the most numerous and equal to $6 \mathrm{~cm}$ and we suggest to take it as a cut-off to classify the lesion as GIANT. Lower values are therefore excluded and considered within the common size of parotid lesions.

- The evolution in malignant tumor of giant pleomorphic adenoma in 20 years is $20 \%$. The absence of surgery leads to an increase in the size of the neoformation, an increased risk of cancer evolution that confirms the need of surgery in such lesions. Keywords: Parotid Gland; Salivary Gland; Giant 


\section{Introduction}

Salivary gland tumors are a morphologically and clinically diverse group of neoplasms which may present significant diagnostic and management challenges.

$70 \%$ of salivary neoplasms affect the parotid gland. $85 \%$ of parotid masses are benign tumors and $60-80 \%$ of these are pleomorphic adenomas. Malignant salivary gland neoplasms account for more than $0.5 \%$ of all malignancies and approximately $3 \%$ to $5 \%$ of all head and neck cancers [1,2].

Most patients with malignant salivary gland tumors are in their sixth or seventh decade of life $[3,4]$. Among the malignant the most frequent is mucoepidermoid carcinoma, with a frequency of $6.5 \%$ [5].

Parotid tumors are usually slow growing, asymptomatic and the average size reported to be between 2 and $6 \mathrm{~cm}$ [6]. In the literature, some cases of "giant tumors" of the parotid are mentioned, most of them benign, but it is not a clear which entity should be defined as giant.

We have examined all lesions that include the term "giant", in order to find a definition, a size cut-off, epidemiologic and clinical characteristics.

A review of the literature on giant parotid neoplasms has been performed.

The dimension was correlated to histological type, size, age, gender, nationality, primitive benignant or malignant nature, eventual malignant evolution from primitive benignancy, time between clinical onset and giant transformation reported (co-gtr) and between this and treatment.

\section{Materials and Methods}

This systematic review was conducted in accordance with the Preferred Reporting Items for Systematic Reviews and Meta-analyses (PRISMA) statement for reporting systematic reviews. The PubMed, Cochrane and Scopus databases were considered. Articles published since 1989 were analyzed to collect informations on the reperies of the last 30 years. Limitations on language of publication were imposed: only articles in English, Spanish or Italian were considered. Boolean operator 'OR' was used to define and connect the search terms.

\section{Search strategy}

The terms used in the PubMed, Cochrane and Scopus searches were: [giant salivary glands tumor] OR [giant parotid tumor] OR [giant parotid mass] OR [neglected parotid tumor]. The references of the selected articles were manually searched for additional papers to add to the review.

\section{Study selection}

The systematic searches were conducted by one author. Study selection was performed by two authors. Titles and abstracts were read and the studies then assessed against the eligibility criteria. The two authors independently assessed the selected studies for eligibility. Articles that satisfied the criteria were selected for fulltext reading. In the event of disagreement between the authors, the study was selected for full-text reading.

Randomized controlled trials (RCTs), case series, case reports, reviews of the literature, interventional or observational studies were considered and the inclusion criteria were as follows:

- $\quad$ Studies reporting malignant or benign parotid tumors with dimension;

- Definition as "giant", "huge" or other terms that emphasize the dimension of the tumor;

- $\quad$ Primary parotid tumor.

Letters to editor were excluded and the following exclusion criteria were applied:

- Studies without indications about tumor dimension.

Studies that satisfied all of these criteria were included. The eligibility of the selected articles was then assessed. The inter-rater agreement between authors was assessed using the kappa statistics. Any disagreement between the two authors about the eligibility of a study was discussed with a third author.

The dependence between histology (carcinoma ex PA and pleomorphic adenoma) and size is studied with the T-test.

The percentile of variation of carcinoma ex pleomorphic adenoma compaired to all pleomorphic adenoma has been studied with box-plot.

The variables size and age are studied by histogram and boxplot.

The correlation between the quantitative variables taken into consideration is studied regarding "size" and "age", "size" and between "co-gtr".

We studied a scatter-plot regarding age-size and size with the co-gtr. 
We studied the distribution of gender and nationality by boxplot.

\section{Eligibility criteria}

The search of the major databases was performed on December 29, 2019. A total of articles were retrieved (Scopus, $n=395$; PubMed, $\mathrm{n}=184$; Cochrane Library, $\mathrm{n}=0$ ). After the selection of eligible papers identified in the main search, a manual search of the reference lists of these studies was conducted.

The titles and abstracts of the 579 articles retrieved in the main search were read independently by the two investigators. Of these, 530 articles were excluded on the basis of their title and abstract, resulting in the reading of 49 full-text articles ( 40 from scopus, 9 from pubmed). Of these papers, 39 (34 from scopus and 5 from pubmed) and 0 from the manual search were included in the review. The inter-rater agreement coefficient was $\mathrm{k}=1$.

The variables that studied are six: histological type, size, age, gender, nationality, time since clinical onset to giant transformation reported (co-gtr).

The data of the variables age, co-gtr and size have been approximated and then the values with decimals below 0.49 have been rounded down while those above 0.50 have been rounded up.

\section{Results}

The data extracted from the studies are listed in table 1 and 2. A total number of 43 patients with giant parotid tumor were retrieved from the considered studies.

The study analyzed 37 out of 39 articles that are case reports and 2 articles that are case series. Patients were 21 male (49\%) and 22 female (51\%) (Table 1).

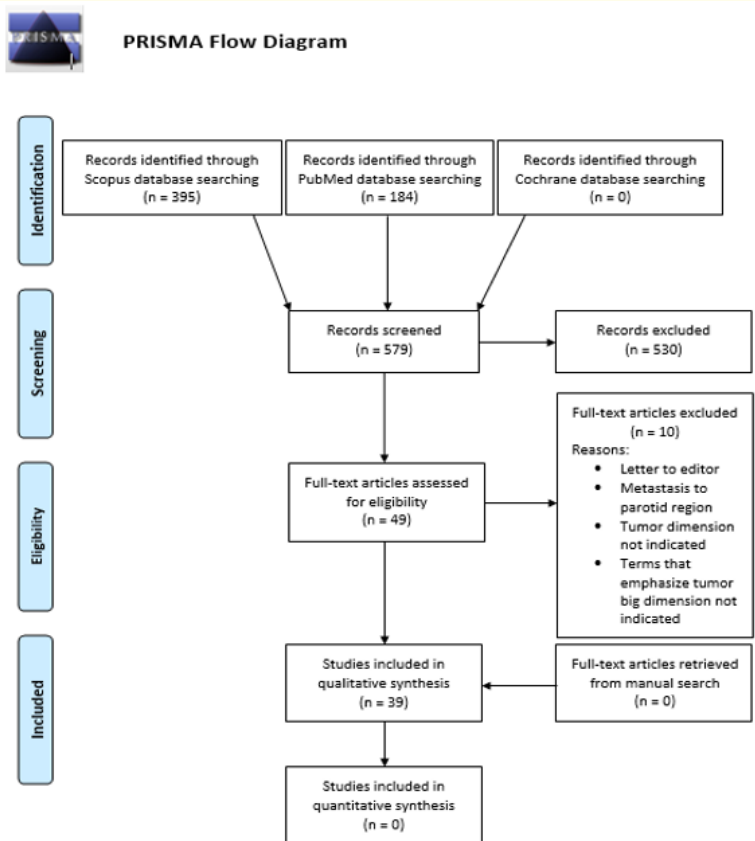

Figure 1

The average size of the tumors was $14.2 \mathrm{~cm}$ and an average age of the patients of 56.46 years (min 1 month, max 92 years).

17 articles report the reason for the therapeutic delay. Of these 17,8 are attributable to socioeconomic problems and 9 for fear of surgery (Table 2).

Such economics problems affected 8 patients from 8 different hospitals ( 1 for country): Nigeria, India, Italy, Turkey, China, Brazil, Bulgaria and Sri Lanka.

The proposal surgical therapy was refused by 9 patients.

These patients came from Spain, Bangladesh, Germany, Taiwan, Japan, Israel (born in Yugoslavia) USA, Romania and Turkey.

\begin{tabular}{|l|c|c|c|c|c|c|}
\hline Article & Size & Type & Age & Gender & Nationality & $\begin{array}{c}\text { Clinical onset to giant } \\
\text { transformation }\end{array}$ \\
\hline$[15]$ & 20 & Warthin & 58 & $\mathrm{~m}$ & India & 20 years \\
\hline$[16]$ & 9 & Sialolipoma & 1 & $\mathrm{~m}$ & Turkey & 7 months \\
\hline$[17]$ & 18 & Dermatofibrosarcoma & 38 & $\mathrm{f}$ & Kazakhstan & 8 years \\
\hline$[18]$ & 10,2 & Pleomorphic adenoma & 57 & $\mathrm{~m}$ & Vietnam & 14 months \\
\hline$[19]$ & 8,4 & Pleomorphic sarcoma & 19 & $\mathrm{~m}$ & India & 2 months \\
\hline$[20]$ & 20 & Pleomorphic adenoma & 72 & $\mathrm{f}$ & Spain & 6 years \\
\hline$[21]$ & 25 & Pleomorphic adenoma & 60 & $\mathrm{~m}$ & Nigeria & 10 years \\
\hline$[22]$ & 20 & Pleomorphic adenoma & 92 & $\mathrm{~m}$ & India & 25 years \\
\hline$[23]$ & 6,5 & Pleomorphic Adenoma & 40 & $\mathrm{f}$ & India & 6 months \\
\hline$[24]$ & 33 & Pleomorphic Adenoma & 83 & $\mathrm{~m}$ & Italy & 30 years \\
\hline
\end{tabular}




\begin{tabular}{|c|c|c|c|c|c|c|}
\hline & & $\begin{array}{c}\text { Squamous cell } \\
\text { carcinoma (SCC) ex }\end{array}$ & & & & \\
\hline \multirow[t]{2}{*}{ [25] } & 20 & Pleomorphic adenoma & 72 & $\mathrm{~m}$ & Bangladesh & 20 years \\
\hline & & Carcinoma ex & & & & \\
\hline [26] & 14 & Pleomorphic adenoma & 82 & $\mathrm{f}$ & Turkey & 20 years \\
\hline \multirow[t]{2}{*}{ [27] } & 8 & Lipoma & 63 & $\mathrm{~m}$ & Iran & 11 years \\
\hline & & Solitary fibrous tumor & & & & \\
\hline [28] & 18 & (sarcoma) & 67 & $\mathrm{f}$ & Romania & 10 years \\
\hline [29] & 7 & Pleomorphic adenoma & 42 & $\mathrm{~m}$ & Ireland & 1 year \\
\hline [30] & 20 & Pleomorphic adenoma & 55 & f & Turkey & 20 years \\
\hline$[31]$ & 6,5 & Pleomorphic adenoma & 41 & $\mathrm{f}$ & Spain & 6 months \\
\hline$[32]$ & 5,5 & Pleomorphic adenoma & 34 & $\mathrm{~m}$ & Spain & 1 month \\
\hline$\left[{ }^{33}\right]$ & 5 & Pleomorphic adenoma & 41 & $\mathrm{f}$ & Spain & 3 months \\
\hline$[34]$ & 11,5 & Warthin & 72 & $\mathrm{~m}$ & Spain & 15 years \\
\hline$[35]$ & 7 & Pleomorphic adenoma & 43 & $\mathrm{f}$ & Germany & 6 months \\
\hline$[36]$ & 8 & Lipoma & 75 & f & Korea & 3 years \\
\hline \multirow[t]{2}{*}{ [37] } & 46 & Fibrolipoma & 55 & f & China & 40 years \\
\hline & & $\begin{array}{c}\text { Epithelial- } \\
\text { myoepithelial }\end{array}$ & & & & \\
\hline$[38]$ & 20 & Carcinoma & 89 & f & Germany & 2 years \\
\hline [39] & 28 & Pleomorphic adenoma & 78 & $\mathrm{~m}$ & Brazil & 30 years \\
\hline$[40]$ & 5,8 & Pleomorphic adenoma & 38 & $\mathrm{f}$ & Italy & 5 months \\
\hline$[41]$ & 5,1 & Pleomorphic adenoma & 36 & $\mathrm{~m}$ & Italy & 1 year \\
\hline$[42]$ & 3 & Pleomorphic adenoma & 42 & $\mathrm{~m}$ & Italy & 2 months \\
\hline [43] & 17 & Fibromyxoid sarcoma & 57 & $f$ & Bulgaria & 2 years \\
\hline \multirow[t]{2}{*}{ [44] } & 9 & Fibrolipoma & 71 & $\mathrm{f}$ & Taiwan & 10 years \\
\hline & & Carcinoma ex & & & & \\
\hline$[45]$ & 33 & pleomorphic adenoma & 72 & $\mathrm{f}$ & Japan & 20 years \\
\hline$[46]$ & 20 & Pleomorphic adenoma & 76 & $\mathrm{~m}$ & Sri Lanka & 30 years \\
\hline$[47]$ & 13 & Pleomorphic adenoma & 63 & $\mathrm{~m}$ & Greece & 30 years \\
\hline$[48]$ & 10 & Warthin & 79 & $\mathrm{~m}$ & Israel & 21 years \\
\hline$[49]$ & 6 & Pleomorphic adenoma & 48 & $\mathrm{f}$ & Spain & 30 years \\
\hline \multirow[t]{2}{*}{ [50] } & 26 & Pleomorphic adenoma & 85 & f & USA & 20 years \\
\hline & & Carcinoma ex & & & & \\
\hline$[51]$ & 12 & Pleomorphic adenoma & 71 & f & Turkey & 20 years \\
\hline$[52]$ & 6 & Heamngioma & $\begin{array}{c}1 \\
\text { month }\end{array}$ & & & \\
\hline$[53]$ & 26 & Pleomorphic adenoma & 81 & $\mathrm{f}$ & Romania & 20 years \\
\hline$[54]$ & 15 & Neurofibroma & $\begin{array}{c}11 \\
\text { month }\end{array}$ & $\mathrm{f}$ & India & 2 months \\
\hline$[55]$ & 8,1 & Giant cell angiofibroma & 29 & $\mathrm{~m}$ & China & 1 year \\
\hline$[56]$ & 6,2 & Giant cell-rich osteosarcoma & 62 & $\mathrm{~m}$ & USA & 2 months \\
\hline$[57]$ & 7 & Fibrosarcoma & 88 & $\mathrm{f}$ & Brazil & na \\
\hline
\end{tabular}

Table 1: Articles analyzed. 


\section{Histology of tumors}

With regards to histology 14 different patterns were noted: 5 ex pleomorphic adenoma (12\%), 1 dermatofibrosarcoma, 1 epithelial-myoepithelial carcinoma (2\%), 3 fibrolipoma (7\%), 1 giant cell angiofibroma (2\%), 1 giant cell-rich osteosarcoma (2\%), 1 hemangioma (2\%), 2 lipoma (5\%), 1 neurofibroma, 20 pleomorphic adenoma (47\%), 2 pleomorphic sarcoma (5\%), 1 sarcoma (2\%), 1 sialolipoma (2\%) and 3 warthin's (7\%).

A two-sample T-test was used, the p-value is greater than 0.05 , the null hypothesis is therefore rejected at a level of significance of $5 \%$.

\section{Comparison between size and histology}

Carcinoma ex pleomorphic adenoma has an average size of 21 $\mathrm{cm}$, dermatofibrosarcoma of $28 \mathrm{~cm}$, epithelial-myoepithelial carcinoma of $20 \mathrm{~cm}$, fibrolipoma of $27.5 \mathrm{~cm}, 7 \mathrm{~cm}$ fibrosarcoma, $8 \mathrm{~cm}$ giant cell angiofibroma, $6 \mathrm{~cm}$ giant cell-rich osteosarcoma, $6 \mathrm{~cm}$ hemangioma, $8 \mathrm{~cm}$ lipoma, $15 \mathrm{~cm}$ neurofibroma, $13.6 \mathrm{~cm}$ pleomorphic adenoma, $8 \mathrm{~cm}$ pleomorphic sarcoma, $17.5 \mathrm{~cm}$ sarcoma, $9 \mathrm{~cm}$ sialolipoma and warthin's of $13.7 \mathrm{~cm}$.

The percentage of variation of carcinoma ex pleomorphic adenoma compared to all pleomorphic adenoma is $20 \%$.

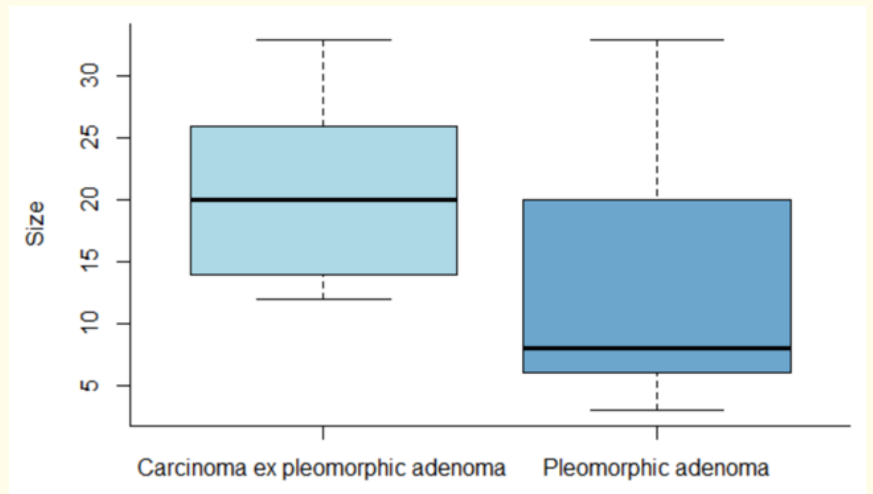

Figure 2: Carcinoma ex pleomorphic adenoma \& Pleomorphic adenoma.

Figure 2: Carcinoma ex pleomorphic adenoma \& Pleomorphic adenoma.

The graph shows a difference in size in pleomorphic adenomas and carcinomas ex pleomorphic adenoma. The variation in pleomorphic adenomas ranges between $3-33 \mathrm{~cm}$ while in carcinomas ex adenoma it ranges from 12 to $33 \mathrm{~cm}$. We can conclude that carcinomas ex pleomorphic adenoma have a larger size than pleomorphic adenomas.
Size

It has been chosen to sort the data for the size variable and approximate them to have a discrete quantitative variable so that the absolute frequencies of the various measurements of the "giant" can be observed.

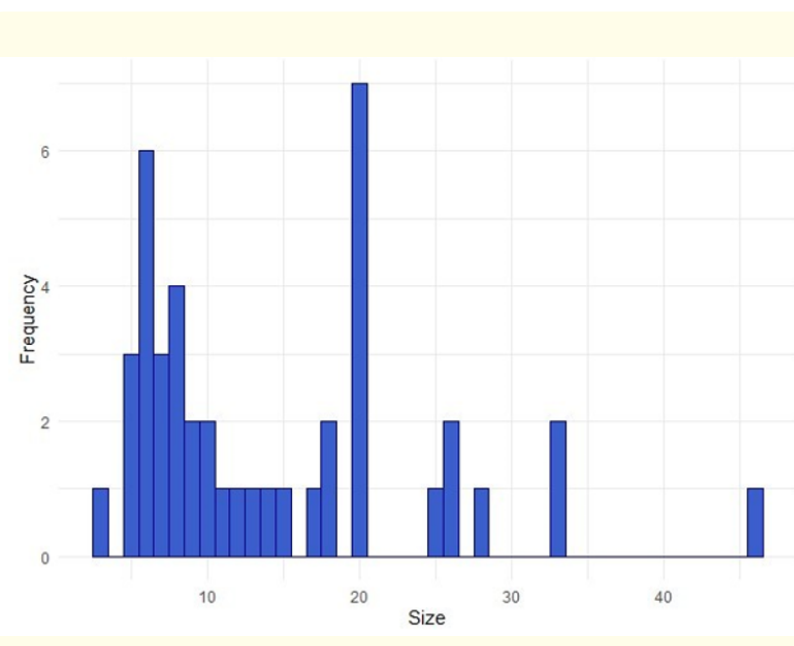

Figure 3: Size.

Looking at the graph, the variable "size" is represented on the $\mathrm{x}$-axis ( $\mathrm{x}$ ) and the absolute frequency is represented on the $\mathrm{y}$-axis (y). Two peaks at $6 \mathrm{~cm}$ and $20 \mathrm{~cm}$ can be observed, so that the previous data can be considered as anomalous data and therefore will not be included in the definition of "giant".

The same variable has been studied also through the boxplot.

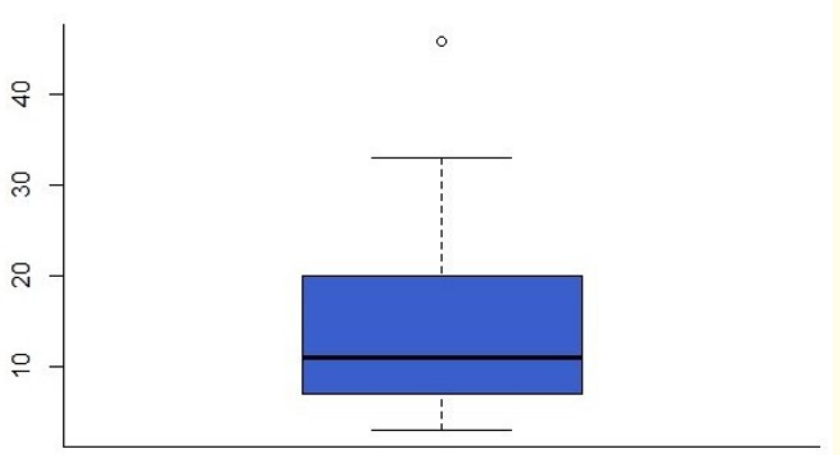

Figure 4: Size.

In the graph of the variable "size" we observe a median equal to $11 \mathrm{~cm}$, the minimum is equal to $3 \mathrm{~cm}$ while the maximum is equal to $46 \mathrm{~cm}$ even if this value can be defined as outlier while the end of 
the whisker is equal to $33 \mathrm{~cm}$; the extremes of the "box" correspond to the first quartile equal to $7 \mathrm{~cm}$ and the third equal to $20 \mathrm{~cm}$.

Age

It has been chosen to sort the data for the variable "age" and approximate them in order to have a quantitative variable in order to observe the absolute frequencies of the ages.

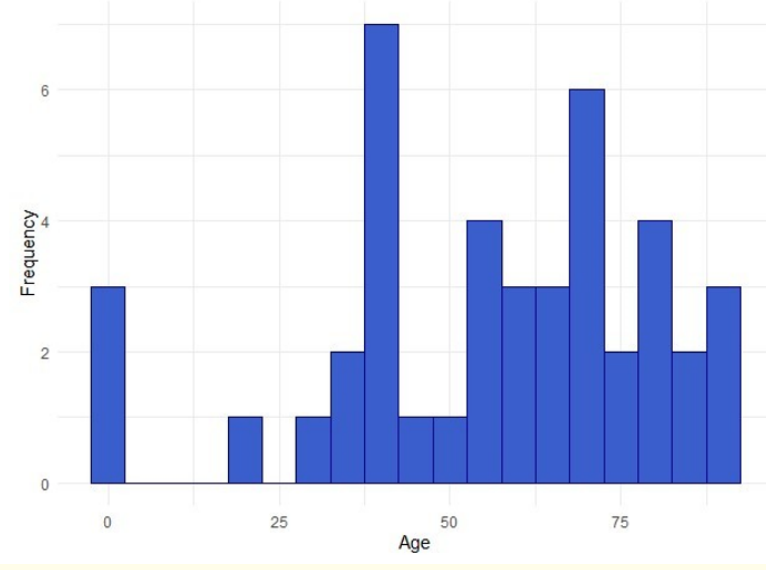

Figure 5: Age.

Looking at the graph, on the $\mathrm{x}$-axis (x) the variable "age" is represented, while on the $\mathrm{y}$-axis ( $\mathrm{y}$ ) the absolute frequency is represented.

The ages have been divided into 5 years in order to be able to observe the available information in an optimal way. From these data a peak between 40 and 45 years is observed.

The same variable, "age", has been studied also through the boxplot.

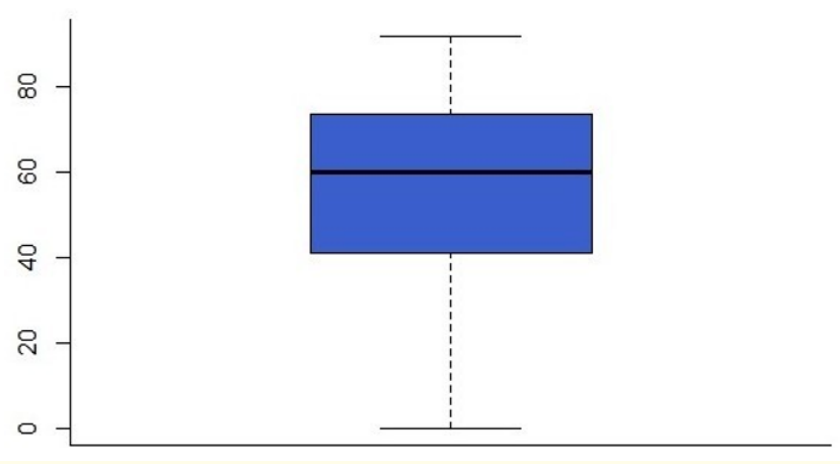

Figure 6: Age.
In the graph of the variable "age" we observe a median equal to 60 years, the minimum is equal to 0 years while the maximum is equal to 92 years; these two values are the extremes of the "moustache" while the extremes of the "box" correspond to the first quartile equal to 41 years and the third equal to 73.5 years. Consequently we can reach the conclusion to take as reference range the age between 41 and 73 years. The previous and subsequent data being few observations can be considered anomalous data and therefore will not be included in the definition of "giant".

\section{Correlations}

The correlation between the quantitative variables taken into consideration is studied.

The correlation index between the variables "size" and "age" is equal to 0.44 , which indicates that the two variables are in agreement, i.e. as one grows, the other grows too.

In the case of the correlation between "size" and "co-gtr" this is high and positive, equal to 0.69 , so as the size increases the number of the time since clinical onset to giant transformation reported and vice versa.

While in case of correlation between " co-gtr " and "age" the correlation is positive and equal to 0.54 .

In the range between 55 and 80 years there are continuous peaks and therefore we can observe that from the age of 50 years and up, with the exception of some values, the size increases with age.

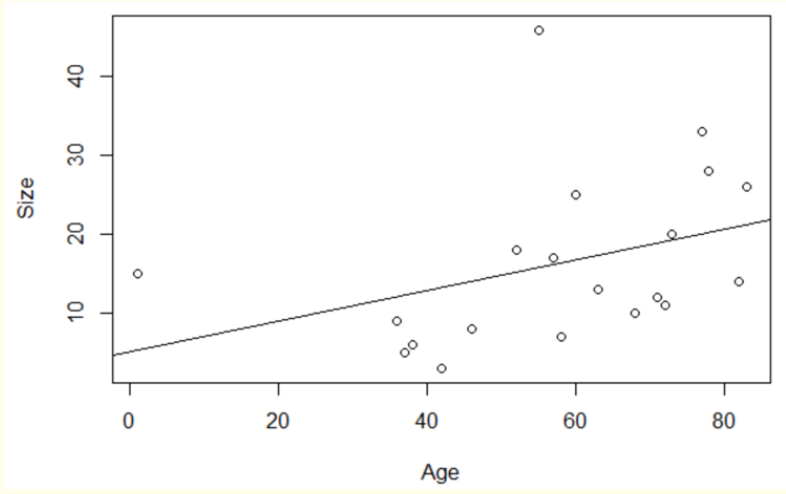

Figure 7: Age-Size.

Observing the scatter-plot with the regression line and assuming a linear relationship of dependence between the two variables it can be said that as the age increases by one year the size 
increases by $0.195 \mathrm{~cm}(\mathrm{P}=0.1168)$. Only $13 \%\left(\mathrm{R}^{\wedge} 2=0.1311\right)$ of the size variability is explained by the explanatory variable age.

In the study of the correlation between "size" and " co-gtr", it can be observed that with the exception of some outliers, the trend especially from 20 years (time since clinical onset to giant transformation reported) and up is increasing. This indicates that the co-gtr, influences size because these tumors are not treated and increase in dimension.

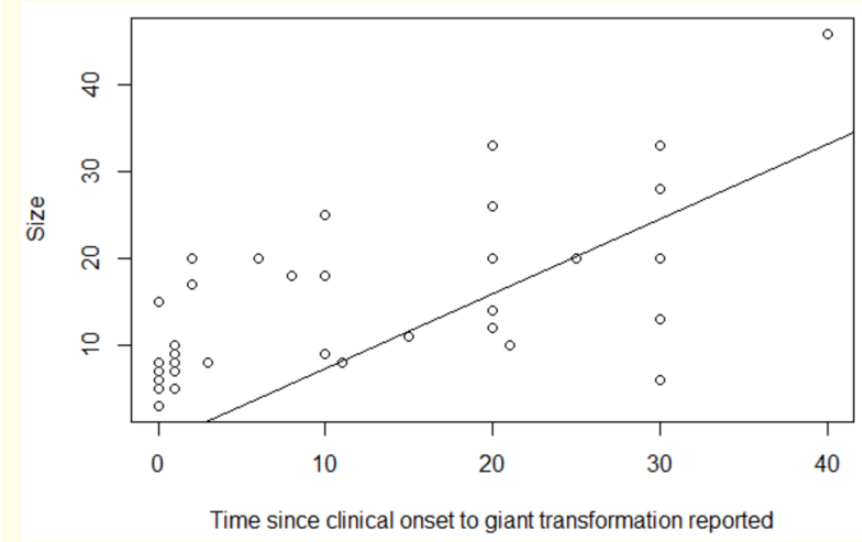

Figure 8: Co-gtr and Size.

Observing the scatter-plot with the regression line and assuming a linear relationship of dependence between the two variables, it can be said that as the time since clinical onset to giant transformation reported increase by one year more, the size increases by $0.86 \mathrm{~cm}(\mathrm{P}=0.013)$. The $48 \%\left(\mathrm{R}^{\wedge} 2=0.4812\right)$ of the size variability is explained by the explanatory variable of co-gtr.

This analysis leads to say that the ratio is statistically significant $(\mathrm{P}<0.05)$.

Gender

Moving on to the study of the variables with respect to the variable "gender" we must define this variable as dichotomous (it assumes only two values " $m$ " and "f"), so we decided to use the boxplots.

The study examined 43 patients, including 21 men (49\%) and 22 women (51\%).

The distributions of the variable "age" with respect to gender are similarly distributed for women and men. The median for women is 57 years old while for men it is 60 years old, first and third quartile differ slightly.

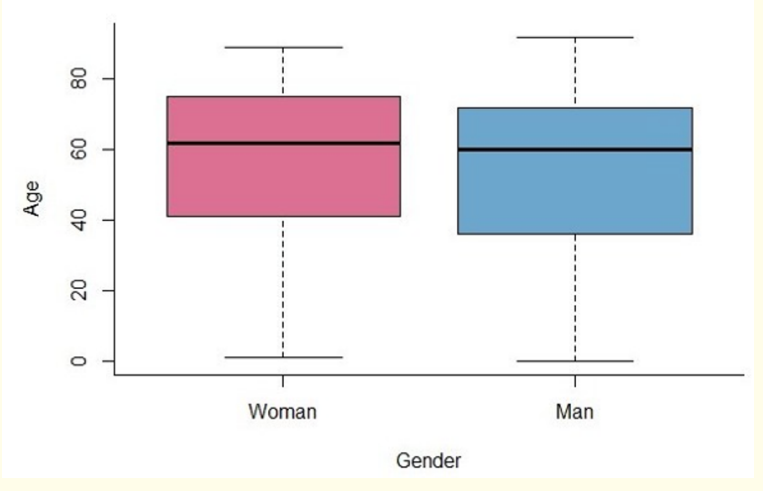

Figure 9: Gender - Age.

\section{Nationality}

The last analysis carried out on these variables is with respect to the continents (Nation- ality). Nations have been divided into 5 categories: Africa (Nigeria), America (Brazil, USA), Asia (Bangladesh, China, India, Iran, Israel, Japan, Kazakhstan, Korea, Sri Lanka, Taiwan and Vietnam), Europe (Bulgaria, Germany, Greece, Ireland, Italy, Romania, Spain and Turkey) and for patients where the Nation was not specified it was decided to put NA or not available.

The patients examined are distributed in 5 countries: 1 patient in Africa (2\%), 4 in America (9\%), 17 in Asia (40\%), 17 in Europe $(40 \%)$ and 4 with an undefined nationality (9\%).

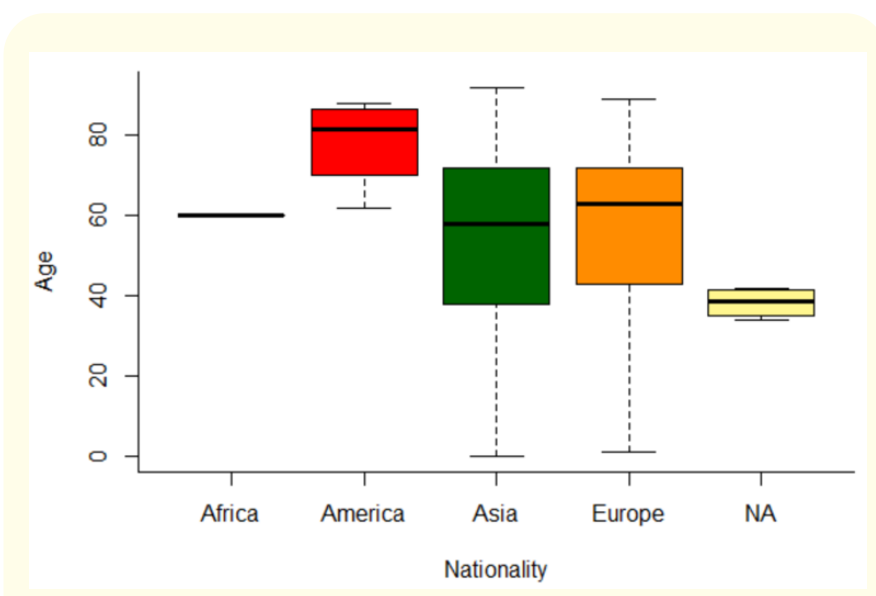

Figure 10: Nationality - Age.

The distribution of "age", differs greatly depending on the continent. The data that is taken as a reference for the comparison is the average, as in the previous analysis, that for Africa having only one observation is equal to 60 years, for America is equal to 81.5 
years, for Asia is equal to 58 years, for Europe is equal to 63 years and finally for NA is equal to 38.5 years.

These data emerged from the analysis are due to the fact that there are few observations and therefore based on these we can say that the patients with higher age are observed in America while those with lower age are those not catalogued in a continent (NA).

\section{Discussion}

Size

- $\quad$ Analyzing the tumors size we obtained an average size of 14.2 $\mathrm{cm}$ and two peaks at $6 \mathrm{~cm}$ and $20 \mathrm{~cm}$. (range $3-46 \mathrm{~cm}$ ). The literature was studied and we found a common size of parotid lesions that is between 2 and $6 \mathrm{~cm}$ [6]. We can indeed have a cut-off to identify Giant parotid lesion differently from common parotid lesion.

- $\quad$ There are the only 2 case series, which have dimensions between 5 and $6 \mathrm{~cm}[36,43]$.

- Between "size" and "co-gtr" it can be observed that the two variables are co-dependent. This indicates that the co-gtr, influences size because these tumors are not treated and increase in size, in other words they are time-dependent.

- It is also observed that size increments by $0.195 \mathrm{~cm}$ every year $(\mathrm{P}=0.1168)$. So there is a continuous increasing in size related to the age of patients and delay of treatment.

- The dependence between age and histology in carcinoma ex pleomorphic adenoma and pleomorphic adenoma it's relevant. There is a strong correlation between the two variables, in fact the degree of connection (Cramer's V index) is equal to $91 \%$ but the result is not statistically significant having a p-value equal to 0.41 .

Gender

- In our review ed there is no prevalence of these tumors in male or female, the ratio was 1:1 (the incidence was $49 \%$ in male and $51 \%$ in female). 21 patients were male (49\%) and 22 patients were female (51\%).

- While Schultz-Coulon literature review of 1989 reported 31 patients ( 20 women $=64.5 \%$ and 11 men $=35.5 \%$ ) with giant tumours of the parotid gland with histological type of pleomorphic adenoma [7].

Age

- $\quad$ The age of the first tumor manifestation varied between 20 and 40 years [7].
- An average age of the patients of 56.46 years (range 1 month92 years) and a peak between 40 and 45 years is observed in our study.

There aren't significant variation

As said before, these two variables do not have a strong correlation, but in the range between 55 and 80 years there are continuous peaks and therefore we can observe that from the age of 50 years and up, with the exception of some values, the size increases with age. At the same time it can be observed that in the age range from 0 to 35 years old the size decreases as the age increases. Therefore, from the observations we have available at the moment what emerges is that a not high correlation between age and size exists, but it could be due to the few observations available on the subject.

\section{Histology}

- $\quad$ Spiro have reviewed a 35-year experience with 2,807 patients treated for salivary tumors which arose in the parotid gland (1,695 patients; $70 \%)$, submandibular gland (235 patients; $8 \%$ ), and seromucinous glands of the upper aerodigestive tract (607 patients; 22\%). Pleomorphic adenomas comprised $45 \%$ of the total, most of which occurred in the parotid gland [8].

- This data are similar to what we found in our review, considering the percentage of pleomorphic adenoma that 47\% (20 of these 43 tumors are PA). Of these tumors, 12 of 43 tumor are malignant and half of them are Carcinoma Ex Pleomorphic Adenoma.

- $\quad$ Approximately $80 \%$ of parotid masses are benign; of these, $80 \%$ are pleomorphic adenomas. These tumors are almost uniformly characterized by a slow-growing [9]. As we analyzed in the review, only 2 cases appears to be characterized by a fast development and malignant histology.

- Schultz-Coulon analyzed the transformation of giant PA in carcinoma; in 3 cases $(=10 \%)$ malignant areas were found within the tumor [7].

- Auclair Pl., et al. concluded that malignant transformation in pleomorphic adenoma ranges from $1.9 \%$ to $23.3 \%$ [10].

- The risk increases in tumours with long-standing evolution, recurrence, advanced age of the patient and location in a major salivary gland [11].

- According to Eneroth and Zettemberg, the risk of malignant transformation increases from $1.6 \%$ in tumours with less than 5 years of evolution, to $9.5 \%$ for those present for more than 15 years [12]. 
- All the giant pleomorphic adenomas analyzed in our review appear to be with long latency and in $20 \%$ of cases with an evolution in malignant in 20 years [14-16].

\section{Reasons of delay}

It appears that at all times erroneous information and action on the part of the family physician has been one of the main reasons for postponing surgical treatment for too long [7].

The reasons of this delay is explained by the patients to two major reasons (others are not reported): socio-economical problems ( 8 patients) and the refusal of surgical therapy ( 9 patients).

Analyzing the long development of these tumors, we assume a psychological problem in giant lesions, rather than a problem of accessibility to surgical treatment, as many patients in countries with good health systems were not treated. The reason in more than half of the cases is to be traced into fear of surgery $[7,8]$.

\section{Conclusion}

- From our review we can state that.

- $\quad$ Giant lesions are more frequent between 41 and 73 years, with a peak between 40 and 45 years.

- The suggested dimensional cut off for the term "giant" can be set at $6 \mathrm{~cm}$.

- Apparently there is no geographical prevalence but this might also connected to the shortage of reports from undeveloped countries.

- No sex prevalence was noted.

- The histology is still more frequently benign, despite some cases with malignant evolution, always time related.

- The average time since clinical onset to giant transformation reported, resulting in 7 years.

- We have found a $20 \%$ of evolution in malignant tumor of giant pleomorphic adenoma in 20 years), this rate is higher to the rates found in literature for normal-sized tumors. The absence of surgery leads to an increased size of the neoformation, a higher risk of cancer evolution, for these reasons timely surgery in salivary gland neoplasm is always advisable.

\section{Bibliography}

1. Speight PM and Barrett AW. "Salivary gland tumours". Oral Disease 8.2 (2002): 229-240.

2. George, K. "Surgical Techniques for Parotid and Submandibular Glands and Ranulae". Maxillofacial Surgery (2017): 686699.
3. Jaber MA. "Intraoral minor salivary gland tumors: a review of 75 cases in a Libyan population". International Journal of Oral and Maxillofacial Surgery 35 (2006): 150-154.

4. Jones AV., et al. "The range and demograph- ics of salivary gland tumours diagnosed in a UK population". Oral Oncology 44 (2008): 407-417.

5. Bouaity B., et al. "Predictors of malignancy in the management of parotid tumors: about 76 cases". The Pan African Medical Journal 23 (2016): 112.

6. Buenting JE., et al. "Giant pleomorphic adenoma of the parotid gland: case report and review of the literature". Ear Nose Throat Journal 77.8 (1998): 634.

7. Schultz-Coulon HJ. "Pleomorphe Riesenadenome der Glandula parotis Pleomorphic giant adenomas of the parotid gland". Laryngorhinootologie 68.8 (1989): 445-449.

8. Spiro RH. "Salivary neoplasms: overview of a 35-year experience with 2,807 patients". Head and Neck Surgery 8.3 (1986): 177-184.

9. Phillips DE and Jones AS. "Reliability of clinical examination in the diagnosisofparotidtumors". The Royal College of Surgeons of Edinburgh 39.2 (1994): 100-102.

10. Auclair Pl and ellis gl. "Atypical features in salivary gland mixed tumors: their relationship to malignant transformation". Modern Pathology 9 (1996): 652-657.

11. yamamoto y. "Clinical signs and histology of carcinoma in pleomorphicadenoma”. Otologia 87: 1320-13204.

12. Eneroth $\mathrm{Cm}$ and Zetterberg A. "Malignancy in pleomorphic adenoma. A clinical and microspectrophotometric study". Acta Oto-Laryngologica 77 (1974): 426-432.

13. Nouraei SAR., et al. "Metastasizing Pleomorphic Salivary Adenoma". Archives of Otorhinolaryngology-Head and Neck Surgery 132.7 (2006): 788-793.

14. Som PM Shugar., et al. "Benign and malignant parotid pleomorphic adenomas: CT and MRI studies". Journal of Computer Assisted Tomography (1988): 1265- 1269.

15. Batsakis JG. "Malignant element tumor”. Annals of Otology, Rhinology and Laryngology 91 (1982;): 342-343

16. Gnepp DR. "Malignant element tumours of the salivary glands: a review". Pathology Annual 28 (1993): 279- 328

17. Bittar RF., et al. "Facial paralysis after superficial parotidectomy: analysis of possible predictors of this complication". Brazilian Journal of Otorhinolaryngology 82.4 (2016): 447-451. 
18. Tian Z., et al. "Salivary gland neoplasms in oral and maxillofacial regions: a 23-year retrospective study of 6982 cases in an eastern Chinese population". International Journal of Oral and Maxillofacial Surgery 39 (2010): 235-242.

19. Luna MA. "Salivary mucoepidermoid carcinoma: revisited". Advances in Anatomic Pathology 13.6 (2006): 293-307.

20. Salaria N., et al. "Giant Warthin's Tumour of the Parotid Gland: A Rare Case Report". Indian Journal of Otolaryngology and Head and Neck Surgery 71.1 (2019): 839-843.

21. Erdăg TK., et al. "Giant Congeni- tal Sialolipoma of Parotid Gland with Parapharyngeal Extension". Journal of Otorhinolaryngology 31.103 (2019): 119-122.

22. Adilbay D., et al. "A case of aggressive giant dermatofibrosarcoma protuberance occurring in the parotid gland". International Journal of Surgery Case Reports 55 (2019): 58-61.

23. Quang V., et al. "A case report of minimal access approach to a giant parapharyngeal space tumor". International Journal of Surgery Open 13 (2018): 6-9.

24. Rai DV., et al. "Undifferentiated pleomorphic sarcoma of the left parotid gland: a case report".

Oral Radiology 33 (2017): 76-80.

25. Calvo-Henriquez, C. E., et al. "Giant Pleomorphic Adenoma of the Parotid Gland". Acta Otorrinolaringologica (English Edition), 67.6 (2016): e40-e41.

26. Akintububo O B., et al. "Giant parotid pleomorphic adenoma in a Nigerian male". Nigerian Journal of Clinical Practice 19 (2016): 681-684.

27. Santosh K. Swain., et al. "An ulcerated giant pleomorphic adenoma of the parotid gland - A case report". Egyptian Journal of Ear, Nose, Throat and Allied Sciences 17.2 (2016): 111-114.

28. Datarkar AN and Deshpande A. "Giant Parapharyngeal Space Pleomorphic Adenoma of the Deep Lobe of Parotid Presenting as Obstructive Sleep Apnoea: A Case Report Review of the Diagnostic and Therapeutic Approaches". Journal of Oral and Maxillofacial Surgery 14.3 (2015): 532-537.

29. Tarsitano A., et al. "Giant pleomorphic adenoma of the parotid gland: an unusual case presentation and literature review". ACTA Otorhinolaryngologica Italica 35.4 (2015): 293-296.

30. Begum, S. K., et al. "Squamous Cell Carcinoma Ex Pleomorphic Adenoma of the Parotid Gland A Case Report with Clinicopathological Review". Journal of Medicine 16.2 (2015): 118-121.
31. Ahmet Erim Pamuk., et al. "A neglected giant parotid gland mass: Ex- cision and reconstruction with facial nerve preservation". Otolaryngolo- gia Polska 68.6 (2014): 333-337.

32. Ghodrat Mohammadi and Rezvan Notash. "A rare case of bilobe parotid lipoma: Involving both superficial and deep lobe of parotid". Egyptian Jour- nal of Ear, Nose, Throat and Allied Sciences 15.1 (2014): 69-71.

33. Octavian Chis and Silviu Albu. "Giant Solitary Fibrous Tumor of the Parotid Gland". Case Reports in Medicine 4 (2014).

34. Morariu I., et al. "Giant parotid pleomorphic adenoma in parapharyngeal space causing severe obstructive sleep apnoea". Irish Medical Journal 105.6 (2012): 184-185.

35. C etin MA., et al. "Giant pleomorphic adenoma of the parotid gland. Kulak Burun Bogaz Ihtis Derg”. 22.2 (2012): 116-118.

36. Infante-Cossio P., et al. "Management of parapharyngeal giant pleomorphic adenoma". Journal of Oral and Maxillofacial Surgery 15.4 (2011): 211-216.

37. Fernandez-Barriales M., et al. "Tumor de Warthin gigante". Acta Otorrinolaringologica Española - Journals 62 (2011): 477478.

38. Palluch, F., et al. "The rapid growth of a pleomorphic adenoma of the parotid gland in the third trimester of pregnancy. Journal of Medical Case Reports 5 (2011): 141.

39. Kim Dong-Seok MD., et al. "Surgical Treatment of a Giant Lipoma in the Parotid Gland". Journal of Craniofacial Surgery 20.5 (2009): 1601-1602.

40. Dai XM., et al. "Giant pedunculated fibrolipoma arising from right facial and cervical region". Journal of Oral and Maxillofacial Surgery 67.6 (2009): 1323-1326.

41. Martin H., et al. "Gi- ant epithelial-myoepithelial carcinoma of the parotid gland, Clinical Imaging”. 33.3 (2009): 237-239.

42. Takahama A Jr., et al. "Giant pleomorphic adenoma of the parotid gland”. Medicina Oral, Patologia Oral, Cirugia Bucal 13.1 (2008): E58-60.

43. Sergi B., et al. "Giant deep lobe parotid gland pleomorphic adenoma involving the parapharyngeal space. Report of three cases and review of the diagnostic and therapeutic approaches". Acta Otorhinolaryngology 28.5 (2008): 261-265.

44. Botev B., et al. "A giant sarcoma of the parotid gland: a case report and review of the literature". In Vivo 20.6B (2006): 907910. 
45. Wu CW., et al. "Giant lipoma arising from deep lobe of the parotid gland". World Journal of Surgical Oncology 4 (2006): 28.

46. Honda T., et al. "Giant pleomorphic adenoma of the parotid gland with malignant transformation". Annals of Plastic Surgery 55.5 (2005): 524-527.

47. M.N de Silva., et al. "A case of giant pleomorphic adenoma of the parotid gland". Oral Oncology Extra 40.3 (2004): 43-45.

48. D. PANOUSSOPOULOS., et al. "Giant Pleomorphic Adenoma of the Parotid Gland Involving the Parapha- ryngeal Space Treated by a Totally Extraoral Transparotid Approach". Journal of Surgical Oncology 81 (2002): 155-157

49. Zeev Abraham., et al. "Skin Ulcerat the Blunt Apex- of a Giant Warthin's Tumor". The Journal of Dermatology 27 (2000): 523528.

50. CASE REPORTS. "Giant parotid pleomorphic adenoma involving the parapharyn- geal space: Report of a case Javier Rodr'iguez-Ciurana". Carlos Bassas 58 (2000): 1184-1187.

51. Akgüner M., et al. "Malignant mixed tumor of the parotid with myoepithelial carcinomatous and papillary adenocarcinomatous com- ponents". Annals of Plastic Surgery 39.6 (1997): 656658.

52. Takato T., et al. "Giant hemangioma of the parotid gland associated with Kasabach-Merritt syndrome: a case report". Journal of Oral and Maxillofacial Surgery 51.4 (1993): 425-428.

53. Lung T and Juncar M. "Carcinoma ex-pleomorphic adenoma - a giant tumor. Chirurgia (Bucur)”. 108.2 (2013): 273-276.

54. Dwivedi S., et al. "Giant solitary neurofibroma presenting as a neck mass in an infant". Journal of Neurosciences in Rural Practice 1.1 (2010): 32-34.

55. He Y., et al. "Giant cell angiofibroma misdiagnosed as a vascular malformation and treated with absolute alcohol for one year: a case report and review of the literature". World Journal of Surgical Oncology 117 (2014).

56. Huang EC., et al. "Giant cell-rich osteosarcoma of the parotid gland: An exceptionally rare entity at an unusual site". Diagnostic Cytopathology 44.12 (2016): 1107-1111.

57. Takahama A Jr., et al. "Nonlymphoid mesenchymal tumors of the parotid gland". Oral Oncology 44.10 (2008): 970-974.

\section{Assets from publication with us}

- Prompt Acknowledgement after receiving the article

- Thorough Double blinded peer review

- Rapid Publication

- Issue of Publication Certificate

- High visibility of your Published work

Website: www.actascientific.com/

Submit Article: www.actascientific.com/submission.php

Email us: editor@actascientific.com

Contact us: +919182824667 